\title{
The pathophysiology of eosinophilic esophagitis
}

\author{
Mayumi Raheem ${ }^{1}$, Steven T. Leach ${ }^{1}$, Andrew S. Day ${ }^{2}$ and Daniel A. Lemberg 1,3* \\ 'School of Women's and Children's Health, University of New South Wales, Sydney, NSW, Australia \\ ${ }^{2}$ Department of Pediatrics, University of Otago (Christchurch), Christchurch, New Zealand \\ ${ }^{3}$ Department of Gastroenterology, Sydney Children's Hospital, Sydney, NSW, Australia
}

Edited by:

André Hoerning, University Children's

Hospital Essen, Germany

Reviewed by:

George N. Konstantinou, 424 Military

Medical Training Hospital, Greece

Helen M. Evans, Starship Children's

Hospital, New Zealand

\section{${ }^{*}$ Correspondence:}

Daniel A. Lemberg, Department of

Gastroenterology, Sydney Children's

Hospital, High Street, Randwick,

Sydney, NSW 2031, Australia

e-mail: daniel.lemberg@

health.nsw.gov.au
Eosinophilic esophagitis (EoE) is an emerging disease characterized by esophageal eosinophilia (>15eos/hpf), lack of responsiveness to acid-suppressive medication and is managed by allergen elimination and anti-allergy therapy. Although the pathophysiology of EoE is currently unsubstantiated, evidence implicates food and aeroallergen hypersensitivity in genetically predisposed individuals as contributory factors. Genome-wide expression analyses have isolated a remarkably conserved gene-expression profile irrespective of age and gender, suggesting a genetic contribution. EoE has characteristics of mainly $T_{H} 2$ type immune responses but also some $T_{H} 1$ cytokines, which appear to strongly contribute to tissue fibrosis, with esophageal epithelial cells providing a hospitable environment for this inflammatory process. Eosinophil-degranulation products appear to play a central role in tissue remodeling in EoE. This remodeling and dysregulation predisposes to fibrosis. Mastcell-derived molecules such as histamine may have an effect on enteric nerves and may also act in concert with transforming growth factor- $\beta$ to interfere with esophageal musculature. Additionally, the esophageal epithelium may facilitate the inflammatory process under pathogenic contexts such as in EoE. This article aims to discuss the contributory factors in the pathophysiology of EoE.

Keywords: eosinophilic esophagitis, celiac disease, pathophysiology

\section{INTRODUCTION}

Eosinophilic esophagitis (EoE) is an emerging condition characterized by severe isolated eosinophilic infiltration of the esophageal mucosa (1). It is unresponsive to acid-suppressive medication but responsive to the removal of dietary antigens and steroid anti-inflammatory medications (2). The identification of EoE as a disease occurred following investigations into treatment resistant patients with gastro-esophageal reflux disease (GERD) (3). The similarity in presentation of EoE and GERD necessitates the correlation of clinical and pathological findings and the establishment of diagnostic criteria differentiating the two diseases, to ensure accurate diagnosis and management (4).

The most recently updated consensus recommendations from The First International Gastrointestinal Research Symposium (FINGERS) state that EoE is a chronic clinicohistopathological disorder characterized by a myriad of symptoms distinct and similar to those of GERD (5). Clinically, EoE symptomatology varies with age, but is characterized by symptoms suggestive of esophageal dysfunction including dysphagia, abdominal pain, and episodes of food impactions. Children typically present with failure to thrive, vomiting, and heartburn (6).

Research has also identified specific endoscopic and histologic features more characteristic of EoE than GERD. Endoscopic findings such as rings, strictures, narrowed esophagus, linear furrows, crepe-paper mucosa, and white plaques along with histological findings such as maximal eosinophil counts greater than 15 eosinophils per high-powered-field (hpf), eosinophil microabscesses, eosinophil degranulation, spongiosis, and subepithelial fibrosis are more common in EoE patients than those with $\operatorname{GERD}(6,7)$.

However, emerging evidence questions the reliability of using eosinophil counts as diagnostic of EoE. Some cases of GERD also meet these criteria of eosinophil numbers, indicating that this feature alone would introduce error in distinguishing EoE from GERD (6). While historically, unresponsiveness to acidsuppression therapy with high esophageal eosinophil density was pathognomonic of EoE, studies now show molecular and histological features that differentiate EoE from GERD (6). Increased awareness of features that define EoE has allowed more accurate diagnoses and enhanced management of patients.

Frequently, but not always, patients presenting with EoE have a history of food (8) or aeroallergen (9) hypersensitivity, elevated serum immunoglobulin (Ig)E, and responsiveness to diet restriction $(8,10)$ or anti-allergy therapy $(11,12)$. However, some patients with EoE have normal IgE levels. While the documented cytokine expression profile in the esophageal tissue in patients with EoE is that of a $\mathrm{T}_{\mathrm{H}} 2$ inflammatory response (13), $\mathrm{T}_{\mathrm{H}} 1$ cytokines have also been shown to be up-regulated in some patients. The later favors a type IV hypersensitivity (cell mediated) mechanism, and may explain the non-IgE cases of EoE (14).

This article aims to discuss the current understanding of the roles of eosinophils, mast cells, cytokines, chemokines, and esophageal epithelial cells, in the pathophysiology of EoE.

\section{EPIDEMIOLOGY}

A number of studies have determined the prevalence of EoE in selected populations: some have suggested an increasing incidence 
of disease. The estimated prevalence of EoE in a pediatric population in Hamilton County, Ohio between 2000 and 2003, was $\sim 4$ in 10,000 with an incidence of $0.9-1.3$ in 10,000 new cases per year (15). A 16-year long study on an adult Swiss cohort observed similar prevalence $(\sim 2 / 10,000)$ and incidence $(1.4 / 100,000)$ rates $(16)$. However, despite the increase in esophagogastroduodenal biopsies between 1982 and 1999, a retrospective study examining 666 patients found the incidence of EoE to be relatively stable during this time period (16). As such enhanced disease recognition rather than true increase in disease incidence may be contributing to the emergence of EoE as a high prevalence clinicopathologic entity.

Case reports of EoE are mainly from industrialized countries such as Australia, North America, Europe, and East Asia, with isolated reports from South America. Reports from AfricanAmerican populations have been scarce $(16,17)$. EoE predominates in Caucasian (81\%) (18) middle aged (30-40 years) men (72\%) (17), although cases have been reported from all ages and ethnic backgrounds $(19,20)$. This observed higher disease rate in Caucasians compared to other ethnicities raises questions about race as a confounding factor in the pathophysiology of EoE. In a recent study comparing the clinical presentations of adult patients with EoE, Sperry et al. (17), suggested that African-American patients were younger at diagnosis, were more likely to present with failure to thrive and less likely to have esophageal rings than Caucasian patients. Whether the lower prevalence of the AfricanAmerican population with EoE is attributable to misdiagnosis due to currently unknown presentations or a true lower prevalence, is uncertain. More research is required to fully establish the role of ethnicity in the pathophysiology of EoE.

Research showing seasonal variations of EoE have postulated that environmental factors may modify the presentation of EoE. Some investigators have reported an increase in the incidence of EoE during spring and summer seasons (21). However, these findings are controversial. Hurrel et al. (22) found a high prevalence of esophageal eosinophilia in adult patients living within the colder geographical climates of the US compared to those living in warmer areas. Other similar studies have also not supported seasonal variations (23).

\section{GENETIC HERITABILITY}

Accumulating evidence has shown a strong familial association in EoE (15). Zink et al. (24) reported EoE to span over two generations in five out of seven families studied. In the same study, a longer term follow-up found a family history of EoE in 5 out of 30 patients with the condition. Concordantly, Noel et al. (15) found $6.8 \%$ of 103 pediatric patients with EoE to have a family history of dysphagia. EoE also exhibits a high sibling risk ratio $\left(\lambda_{S}\right)$, defined as the ratio of disease manifestation given that one's sibling is affected, of $\sim 80$, compared to other atopic diseases such as asthma $\left(\lambda_{S} \sim 2\right)(25)$. To allow comparison, inflammatory bowel disease, a condition known to run in families has a $\lambda_{S}$ of 0.83 (26). Interestingly, recent studies have demonstrated the coexistence of EoE with another genetically inherited condition, celiac disease (CD) $(27,28)$, further highlighting a possible genetic contribution to EoE.

Several candidate genes for EoE have been identified. CCL26/eotaxin-3 gene, based on genome-wide association studies
(GWAS), is the most highly expressed gene in EoE, being up-regulated between 50- and 100-fold in EoE patients (29). However, this disease-associated allele has only been found in $14 \%$ of cases (30), highlighting the contributions of other risk variants. More recently, Rothenberg et al. (29) identified and replicated a significant locus at 5q22.1 in European cases of EoE. The two genes that map to this locus are TSLP and WDR36 (29). TSLP encodes a cytokine similar to interleukin (IL)-7 produced in the thymus and peripheral tissues, and acts to regulate $\mathrm{T}_{\mathrm{H}} 2$ responses (31). WD36 is co-regulated with T-cell growth factor IL-2 and has been linked to glaucoma (32). It was postulated that the male predominance of EoE may be related to the TSLP receptor residing within the pseudoautosomal region 1 on the $\mathrm{X}$ and $\mathrm{Y}$ chromosomes (Xp22.3, Yp11.3) (29). A more recent study showed that polymorphisms in TSLP are risk factors for the development of EoE, independent of allergy status and phenotypes (33). The same study found an association between polymorphisms in the thymic stromal lipoprotein receptor $(T S L P R)$ gene on $\mathrm{Xp} 22.3 / \mathrm{Yp} 11.3$ and EoE in male participants, suggesting a mechanism for the male predominance of EoE. Moreover, primary esophageal epithelial cells were shown to express TSLP mRNA in response to toll-like receptor 3 signaling, suggesting a possible contribution of TSLP in the inflammation and proliferation occurring in EoE affected esophagi. Furthermore, in a genome-wide microarray expression analysis, Lu et al. (34) identified 32 miRNA specific for EoE. Of these, miRNA-21 and miRNA-223 were the most up-regulated in untreated EoE and were down-regulated upon corticosteroid administration.

Despite this strong evidence supporting the genetic basis of EoE pathogenesis, studies have shown that the familial pattern of inheritance of EoE shares an underlying pathogenesis with sporadic cases of $\operatorname{EoE}(35)$.

\section{THE PATHOPHYSIOLOGY OF EOE}

Genetic predisposition may deem an individual vulnerable to the environmental triggers resulting in EoE. Frequently, patients presenting with EoE have a history of food (8) or aeroallergen (9) hypersensitivity, elevated serum IgE, and responsiveness to diet restriction $(8,10)$ or anti-allergy therapy $(11,36)$. Food hypersensitivity has been reported in $19-73 \%$ of children and $13-25 \%$ of adults with EoE (37). The reason for lower rates of food hypersensitivity in adults is unclear, but this feature may mean that adults are less responsive to diet restriction (8). Regardless, EoE is considered an immunoallergenic disorder, whereby esophageal inflammation results from repeated exposure to food and aeroallergens in genetically susceptible individuals (38).

The documented cytokine expression profile in the esophageal tissue of EoE patients is that of a $\mathrm{T}_{\mathrm{H}} 2$ inflammatory response (13). The activated $\mathrm{T}_{\mathrm{H}} 2$ response leads to the recruitment and activation of eosinophils and mast cells, which degranulate, releasing products that instigate tissue damage and repair (39). Interestingly, $\mathrm{T}_{\mathrm{H}} 1$ cytokines including tumor necrosis factor (TNF)- $\alpha$ (expressed by esophageal epithelial cells) (39) and interferon (IFN) $-\gamma$ (upregulated by peripheral blood $\mathrm{T}$ cells) (40) are also found in increased numbers in esophageal biopsies (41). This may explain the non-IgE, type IV hypersensitivity (cell mediated) mechanism of EoE (14). It is postulated that the EoE-defining endoscopic and histologic manifestations are a culmination of the disease process 
(15) which, may have debilitating long-term effects including strictures and food impactions in untreated or poorly managed cases of EoE.

\section{EOSINOPHILS}

Eosinophils originate from CD34+ myeloid precursor cells in the bone marrow, mature to a granulated state and migrate to vascular spaces (39). They tend to be present in all layers of the esophagus in EoE, but predominate in the lamina propria and submucosal regions. Eosinophils contain many preformed granule proteins including eosinophil cationic protein (ECP), major basic protein (MBP) eosinophil peroxidase (EPO), and eosinophil-derived neurotoxin $(\mathrm{EDN})$, which are released into tissues upon stimulation and degranulation (42). Additionally, eosinophils synthesize and release cytokines including IL-5, IL-13, transforming growth factor (TGF) $-\alpha$ and $-\beta$, chemokines (eotaxins and RANTES), and lipid mediators such as platelet activating factor (PAF) and leukotriene C4 (42). The process of eosinophil maturation and migration is stimulated by IL-5, IL-13, and granulocyte-macrophage colony stimulating factor (GM-CSF) (9). Eosinophil-derived angiogenic molecules may increase vascularity and facilitate inflammatory cell recruitment. TGF- $\beta 1$ and matrix metalloproteinase 9 (MMP)9 are fibrogenic mediators implicated in airway remodeling (42). Additionally, MBP and MMP-9 have been implicated in the disruption of esophageal epithelial integrity though their involvement in smooth muscles, fibroblasts, and cell-adhesion molecules (43). These processes may culminate in overall esophageal dysfunction through the consequent tissue remodeling.

Eosinophils are considered the main effector cells in fibrosis in a variety of hypereosinophilic syndromes and eosinophil-related allergic diseases including asthma and EoE (44). TGF- $\beta$ (45) and eosinophilic granule proteins MBP and EPO (46) are the key eosinophil effector proteins. The importance of eosinophils in mediating tissue fibrosis is supported by evidence in both murine and human models (26). Interestingly, a recent study on fibrosis reversal with dietary and steroid therapy showed that improvement in esophageal eosinophilia and eosinophil degranulation within the epithelium was strongly associated with fibrosis reversal $(47,48)$ and symptom improvement. This finding is consistent with Kagalwalla et al. (45), who found improvements in epithelial remodeling in both dietary and corticosteroid therapy, and also found these improvements to be directly associated with improvement in esophageal eosinophilia (47). These findings not only highlight the importance of targeting fibrosis reversal in treatment of EoE, but also underline the importance of eosinophils in tissue remodeling.

\section{EOSINOPHIL-DERIVED ANGIOGENIC MOLECULES}

Angiogenesis, a characteristic of chronic inflammation, may facilitate inflammatory cell recruitment (49). Increased numbers of blood vessels are found in the lamina propria of pediatric patients with EoE than those with reflux esophagitis (50). The same study found an increased expression of the endothelial activation marker, vascular cell-adhesion molecule (VCAM)-1, compared with normal control subjects or patients with reflux esophagitis. Moreover, VCAM-1 expression positively correlated $(r=0.61)$ with esophageal eosinophil number, affirming its involvement in
EoE. Increased VCAM-1 expression causes increased tethering of inflammatory cells to the endothelium of esophageal vessels, thereby facilitating eosinophil infiltration into the esophagus (51). Progressive tissue damage may result from this increased inflammatory cell recruitment facilitated by angiogenic products.

\section{EOSINOPHIL-DERIVED TGF- $\beta 1$}

Eosinophil-derived TGF- $\beta 1$ has been implicated in the activation, proliferation, and synthesis of extracellular matrices of epithelial cells (39). Evidence suggests that TGF- $\beta 1$ induces epithelial basal zone hyperplasia, contributing to esophageal wall thickening resulting in luminal narrowing (12). It also induces fibroblast activation and differentiation into myofibroblasts, with consequent over-production of extracellular matrix (ECM), predisposing to subepithelial fibrosis with consequent features of strictures and food impactions (52). Finally, TGF- $\beta 1$ may induce smooth muscle hypertrophy, leading to thickening of the esophageal muscularis propria (53).

Accordingly, TGF- $\beta 1$ would be a good therapeutic target in EoE. However, being a T-regulatory molecule, it is involved in the regulation of normal immune systems and is vital in repair (39). Consequently, the difficulty would lie in the localized delivery of a drug targeting TGF- $\beta 1$ to the esophagus alone, without interfering with its normal functions in other tissues.

\section{MBP AND MMP-9}

Major basic protein levels correlate with basal cell hyperplasia (46) and has been associated with loss of barrier function in the esophageal epithelium (42). MBP has consequently been proposed as a player in subepithelial fibrosis in EoE (54). It appears to function by up-regulating the expression of fibroblast growth factor (FGF)-9, a molecule involved in epithelial homeostasis and proliferative response to injury (11). While initially being uncharacterized in the esophagus, FGF-9 has now been found in biopsy specimens of patients with $\mathrm{EoE}$ (55), hence the interest in its upregulation by MBP. Another function of this molecule is smooth muscle contraction through its action on muscarinic $\mathrm{M}_{2}$ receptors, which may contribute to the dysphagia experienced by many patients with EoE (56).

A molecule with similar function to MBP, MMP-9 can be generated by structural and inflammatory cells and has the ability to secrete and activate latent matrix-bound growth factors (42). MMP-9 can thus degrade proteoglycans thereby enhancing airway fibrosis and smooth muscle proliferation (23). Although current research implicate MBP and MMP-9 in cell proliferation and tissue fibrosis, it must be highlighted that these molecules may have an organ-specific function, in which case their effect on bronchial remodeling may not be able to be generalized to esophageal remodeling.

\section{MAST CELLS}

Mast cells, like eosinophils, are derived from CD34+ progenitors in the bone marrow, with their differentiation being regulated by surface c-kit receptor (CD117) (57). Mast cells contain several preformed mediators including histamine, cytokines, serine proteases (tryptase, chymase), and proteoglycans that are stored in cytoplasmic granules (58). They have a central role in innate 
immunity especially in allergic diseases, being the predominating cells in IgE-mediated responses. Attwood and colleagues (3) first discovered the presence of mast cells in the EoE inflammatory infiltrate. Due to the suggested immunoallergenic nature of EoE, the study of the involvement of mast cells in this disease has recently increased (59).

The role of mast cells in EoE has been supported by both human and animal studies. Several studies have identified increased mastcell numbers in patients with EoE $(46,60,61)$. Further, epithelial mast-cell infiltration was noted to precede eosinophil accumulation in a guinea pig model of EoE (62). Mast-cell numbers were also significantly increased after intranasal exposure to cockroach and dust mite allergen in a murine model of EoE (63). Importantly, studies on humans with EoE have found a correlation between mast-cell counts and characteristic features of EoE including intraepithelial eosinophil numbers, basal zone hyperplasia, and eotaxin-3 level $(30,54)$.

The immunoregulatory function of mast cells has been increasingly recognized in EoE (64). Through its action on $\mathrm{H} 2$ and $\mathrm{H} 4$ receptors, mast-cell-derived histamine has been shown to modulate immune responses by acting on dendritic cells and T-lymphocytes (65). It may act to maintain a favorable environment for allergic immune responses by recruiting T-lymphocytes, enhancing the proliferation of eosinophils in the bone marrow and inducing B-cell class switching to IgE production (66). Additionally, mast-cell-derived proteoglycans such as heparin are known to potentiate eotaxin-induced eosinophil recruitment in vivo (67), highlighting a key combinatory role amongst eosinophils and mast cells in EoE pathogenesis.

Mast cells may also have an effector function through specific enzymes. Mast-cell-specific genes encoding for proteins including chymase, tryptase, and carboxypeptidase A3 are significantly unregulated in EoE (30). These proteins are known to increase mucus secretion and smooth muscle contraction in the bronchi of asthmatics (39). Furthermore, Chehade and colleagues (54) found increased expression of tryptase-positive mast cells that produced TGF- $\beta$ contributing to tissue remodeling. Additionally, mast cells have been found in the muscle layers of the esophagus and may cause contraction of muscularis mucosae through histamine-activated acetylcholine resulting in trachealization of the esophagus, as observed endoscopically in patients with EoE (68).

Despite evidence supporting mast-cell involvement in EoE, there is currently no evidence supporting therapies targeting mast cells in EoE. Lucendo et al. (59) found no statistical decrease in mast-cell numbers in EoE patients following 3 months of glucocorticoid therapy (fluticasone propionate $500 \mu \mathrm{g}$ b.i.d). In the same study however, there was a significant reduction in $\operatorname{IgE}$ positive cells. A randomized controlled trial found a significant decrease in mast-cell numbers in pediatric patients with EoE after 3 months fluticasone treatment with fluticasone $(880 \mu \mathrm{g}$ b.i.d) (69). However, 1-month treatment of EoE in a pediatric cohort, with the mast-cell stabilizer sodium cromoglycate $(100 \mathrm{mg}$ q.i.d), did not significantly affect symptoms or eosinophil counts (2). Overall, this suggests that although the involvement of mast cells is clear, its role in the pathogenesis of EoE is not yet fully characterized.

\section{THE ROLE OF TH2 TYPE INFLAMMATION IN EOE PATHOPHYSIOLOGY}

Serum IgE measurements demonstrate that the majority $(80 \%)$ of patients with EoE have identifiable hypersensitivity to both food and aeroallergens (70). Inferentially, the majority of EoE cases may be associated with an IgE-mediated type 1 hypersensitivity reaction. Such reactions involve antigen presentation to CD4+ T-helper $2\left(\mathrm{~T}_{\mathrm{H}} 2\right)$ cells, which stimulate B-cell class switching to IgE production (39). This differs from $T_{H} 1$ responses where the immune system is directed toward a chronic intracellular infection, involving the activation of cytotoxic $\mathrm{T}$ cells and macrophages by $\mathrm{T}_{\mathrm{H}} 1$ cytokines such as IFN- $\gamma$. Most adaptive immune responses are a mixture of both $\mathrm{T}_{\mathrm{H}} 1$ and $\mathrm{T}_{\mathrm{H}} 2$ however, as suggested by the cytokine expression profile, EoE is a predominantly $\mathrm{T}_{\mathrm{H}} 2$-mediated condition (13). The following section discusses the contributions of $\mathrm{B}$ cells and $\mathrm{T}_{\mathrm{H}} 2$ cytokines such as IL-5 and IL-13 in the pathogenesis of EoE.

\section{B CELLS}

In allergic contexts, $\mathrm{T}_{\mathrm{H}} 2$ cells stimulate $\mathrm{B}$-cell $(\mathrm{CD} 20+)$ class switching to produce IgE antibodies. IgE binds to its respective high-affinity receptor (FCERI) present on the surface of mast cells, and this complex can then bind to an antigen, leading to mastcell activation and degranulation (57). Unfortunately, despite this knowledge of $\mathrm{B}$ cells in allergic reactions, their role in EoE is poorly understood. One study found B cells to be significantly increased in the epithelium and lamina propria of EoE patients compared to healthy controls, and this value correlated significantly $(r=0.744)$ with mast-cell number (71), which in turn has been shown to correlate with eosinophil numbers (54). In Vicario and colleagues (71) study, evidence showed local B lymphocyte class switching to IgE expression (71). Another study found no change in B-cell numbers in untreated or corticosteroidtreated EoE patients (72). The possible discrepancy between the studies may be due to differences in patient demographics, and further such studies are required to substantiate the role of B cells in $\mathrm{EoE}$.

\section{CYTOKINES}

Interleukin-4 is responsible for the differentiation of naïve T-helper $\left(\mathrm{T}_{\mathrm{H}} 0\right)$ cells into activated $\mathrm{T}_{\mathrm{H}} 2$ cells. IL- 4 stimulates $\mathrm{B}$-cell proliferation and maturation within plasma cells, regulates class switching of antibodies, and increases IgE production. Blanchard and colleagues (13) found no significant differences in the level of IL-4 between EoE patients and non-EoE controls, however IL-4 mRNA levels were significantly decreased in EoE patients following glucocorticoid therapy or elemental diets. In the same study, elevated IL-4 and IL-5 mRNA levels were found in allergic EoE patients compared to their non-allergic counterparts. Interestingly, there was no statistical difference in eotaxin-3 or IL-13 mRNA levels between the two patient groups. This may indicate a dysregulation of IL-4 and IL-5 in allergic EoE patients which possibly reflect their systemic allergic history rather than activity of the disease (13). However, this difference in cytokine expression between allergic and non-allergic EoE patients may open avenues for further research such as investigating possible difference in severity and response to treatments between the two patient groups. 
Interleukin-5 functions in the proliferation, differentiation, and survival of eosinophils, $\mathrm{T}_{\mathrm{H}} 0$ cells, and mast cells (39). Mishra et al. (9) demonstrated a murine model for aeroallergen-induced esophageal eosinophilia by challenging mice with Aspergillus fumigatus. In this model, IL-5 was shown to be essential in aeroallergeninduced eosinophil recruitment to the esophagus (73). More recently, Blanchard et al. (13) found a significant increase in IL-5 mRNA in EoE patients compared to inactive EoE and healthy controls. The same study confirmed the importance of eotaxin3 in the IL-5-dependent induction of esophageal eosinophilia as a 15-fold decrease in eosinophil number was found in eotaxindeficient mice when subjected to the same aeroallergen challenge (73). IL-5 appears to function by enhancing eosinophil responsiveness to endogenous chemokines expressed by the esophagus such as eotaxin-3 (discussed later) (73).

Despite compelling evidence suggesting the importance of IL-5 in EoE, drugs targeting IL-5 have shown little clinical efficacy. A randomized controlled trial evaluating the anti-IL-5 antibody mepolizumab showed little clinical improvement, despite the decreased tissue eosinophilia compared to placebo controls (12). This questions current understanding of the mechanism by which IL- 5 contributes to EoE, or that perhaps esophageal damage may prevail through other mechanisms, aside from that of IL-5-recruited eosinophils. Concordantly, reslizumab, another anti-IL-5 antibody reduced eosinophil counts in esophagi of children and adolescents, but symptom improvements were observed in all treatment groups and were not associated with changes in eosinophil number in the esophagus (74).

Interleukin-13, similar in structure and function to IL-4, may have a role in propagating the inflammatory response toward a $\mathrm{T}_{\mathrm{H}} 2$ mechanism, and has also been implicated in tissue fibrosis (39). Interestingly, IL-13-induced lung eosinophilia consequently induced esophageal eosinophilia as well (75), suggesting a possible intimate connection between respiratory and esophageal epithelia, or simply the systemic allergic reaction in both cases. Studies on bronchial remodeling in asthma, have shown that IL-13 is essential for tissue fibrosis and airway mucous production (52). Similar findings were seen in EoE, when Blanchard and colleagues (60) found a 16-fold increase in IL-13 mRNA in biopsies of pediatric patients with esophageal fibrosis, compared to non-EoE controls. IL-13 is also known to stimulate eotaxin-3 production by epithelial cells, which in turn stimulates eosinophil recruitment (60).

Additionally, IL-13 may stimulate fibroblasts to overexpress periostin and down-regulate filaggrin. Periostin is an ECM molecule that promotes eotaxin-induced eosinophil recruitment and regulates eosinophil adhesion (76). Filaggrin is a structural barrier protein in skin keratinocytes; down-regulation of this protein has been implicated in the impairment of esophageal barrier function and development of atopic dermatitis (76). Filaggrin is a member of the epithelial differentiation cluster (EDC), and together with involucrin (another EDC member), prevents the proteolytic destruction of keratin during differentiation of epidermal cells $(77,78)$. This forms an important barrier function in cornified epithelial cells, although its function in esophageal epithelial cells is less clear. A recent study on the effect of IL-13 on genes involved in epithelial differentiation concluded that IL-13 plays a large role in the up-regulation of genes such as Ki67 and down-regulation of EDC genes such as filaggrin and involucrin, which cumulatively contribute to the eotaxin-mediated recruitment of eosinophils to the esophageal epithelium. Not only does this open an avenue for further research on possible therapeutic strategies targeting IL-13 in EoE, but also suggests the importance of IL-13 in the pathogenesis of EoE.

Recently, Zhu et al. (79) found that IL-15 is involved in the induction of eosinophil-selective cytokines and chemokines by CD4+ $\mathrm{T}$ cells. This study found a 6- to 10-fold increase in the levels of both IL-15 and its receptor IL-15R $\alpha$ in esophageal tissues, and a twofold increase in serum IL-15 protein levels in patients with EoE. Additionally, the level of esophageal eosinophilia in patients both treated and untreated EoE correlated significantly with the IL-15 transcript. Importantly, the $I L$-15R $\alpha$-deficient mice were protected from the development of experimental EoE (79). Interestingly however, these mice were not protected from airway inflammation, suggesting that IL-15 many have an organ-specific mechanistic induction of esophageal eosinophilia in mice.

\section{EOTAXINS}

The three eotaxins are chemokines with selective eosinophilchemoattractant activity and act on CCR-3 receptors (39). Blanchard and colleagues (30) found an increase in eotaxin3 levels in esophageal biopsies of patients with EoE. In the same study, these levels correlated with esophageal eosinophil numbers. Konikoff and colleagues (80) found a correlation $(r=0.32)$ between eotaxin-3 protein level in peripheral blood and esophageal eosinophilia. Interestingly, eotaxin-1 and eotaxin2 levels did not correlate. Battacharya and colleagues (81) however showed contradicting findings with increased eotaxin- $1,-2$, and -3 levels in EoE, but also no correlation between eotaxin-3 levels and tissue eosinophilia.

A recent genome-wide expression analysis identified eotaxin-3 as the single most up-regulated gene in EoE (30). Furthermore, a single nucleotide polymorphism in the untranslated region of the eotaxin-3 gene is associated with EoE (30). Interestingly, this expression profile is not associated with GERD, a disease triggered by acid reflux, also associated with esophageal eosinophilia (57). Blanchard et al. (30) found a strong correlation between eotaxin-3 level and disease severity, determined by the degree of basal cell hyperplasia and numbers of eosinophils and mast cells. In the same study, EoE could not be induced in CCR-3-deficient mice (30). Additionally, IL-5 and IL-13 have shown to increase eotaxin-3 release by esophageal epithelial cells (81) suggesting the combined contributions of these molecules in esophageal eosinophilia.

Eotaxin-3 has been increasingly recognized as a more accurate biomarker for the diagnosis of EoE. Some patients with GERD also present with eosinophil numbers $>15 / \mathrm{hpf}$, thus raising questions regarding the accuracy of using peak intraepithelial eosinophil counts as a diagnostic feature of EoE (6). The same study concluded that increased numbers of cells staining for MBP and eotaxin-3 was more predictive of EoE than eosinophil counts alone. This suggests possible flaws in current diagnostic criteria, and highlights the importance of eotaxin-3 in EoE.

Combining this evidence, the importance of eotaxin-3 in esophageal eosinophilia is widely accepted. It is proposed that IL-13, produced by $\mathrm{T}_{\mathrm{H}} 2$ inflammatory cells under allergic contexts 
stimulates the production of eotaxin-3 by epithelial cells. IL- 5 and eotaxin-3 may act synergistically to induce esophageal eosinophil infiltration, allowing eosinophilic inflammation to ensue. However, the reason for which this inflammatory process is restricted to the esophagus remains elusive. Regardless, this localized function of eotaxin-3 in EoE may be important in minimizing side-effects, if it were to be considered a future therapeutic target.

\section{ESOPHAGEAL EPITHELIUM}

The esophagus is composed of stratified squamous epithelium, protected by a variety of organ-specific molecules such as mucous and antibodies. Additionally, the epithelium is a potent reservoir of cytokines and lipid mediators, which normally functions to cleanse the epithelial surface (42). Disease develops when these functions are dysregulated and disrupted (49). In an allergen-induced $\mathrm{T}_{\mathrm{H}} 2$ response, molecules such as IL-13 stimulate esophageal epithelial cells to produce eotaxin-3 (30) which in turn leads to esophageal eosinophil recruitment. The resulting activation and degranulation releases mediators that cause tissue remodeling.

Epithelial to mesenchymal transformation (EMT) is a process whereby epithelia lose many characteristics including polarity, and acquire properties of mesenchymal cells, including motility and loose cell-adhesion (45). It facilitates the development of tissue fibrosis in many organs in response to injury, including the lungs (45). TGF- $\beta$ and MBP released by eosinophils or damaged epithelium, may induce EMT and contribute to subepithelial fibrosis (82). The degree of EMT in patients with EoE has been shown to correlate with the amount of TGF- $\beta 1$, eosinophil number, and amount of subepithelial fibrosis (82). Eosinophils can also directly induce the expression of factors relevant to EMT and fibrosis in epithelial cells, such as TGF- $\alpha$, MMP-9, and others, through the secretion of MBP and cytokines such as IL-13 (45).

Blanchard and colleagues (30) suggested that intestinal epithelia are capable of releasing eotaxins, which are essential in eosinophil migration to the GIT. Epithelia also promote eosinophil survival, by releasing epithelial-derived GMSF, which delays apoptosis (42). Additionally, Hahn and colleagues (83) found that during allergic inflammation, there is an increased expression of nerve growth factor in airway epithelial cells, which may promote the survival of tissue eosinophils. However esophageal epithelial cells may have an organ-specific interaction with eosinophils, as supported in studies showing the necessity of eotaxin-3 in the induction of esophageal eosinophilia $(30,73)$.

Esophageal epithelial cells also express IL-4 $\alpha$, IL-13R $\alpha 1$, and IL-13R $\alpha 2$, which are all the components of the IL-13 receptor, rendering esophageal epithelial cells vulnerable to influence by IL-13. As mentioned previously, IL-13 plays a large role in the eotaxinmediated recruitment of eosinophils to the esophageal mucosa, through the stimulation of epithelial cells to up-regulate some genes and down-regulate others. Interestingly, the same study found that biopsies of normal and EoE diseased esophagi, both showed an over-expression of eotaxin-3 in response to IL-13, suggesting that IL-13/IL-13 receptor/STAT6 pathway is similar in both normal and EoE patients (67).

\section{Table 1 | Key findings and current treatments}

\section{KEY FINDINGS}

EoE is an inflammatory disorder that is most likely initiated by a hypersensitivity reaction to aero- or food allergens, with a late-phase characterized by eosinophil recruitment and subsequent tissue damage

EoE predominates in the Caucasian male population. Mutations in the TSLP gene may provide a mechanism for the male predilection of EoE

Eosinophil-derived molecules including TGF- $\beta 1$, MBP, and MMP-9 play a central role in fibrosis

Some mast-cell-derived molecules such as heparin potentiate eotaxin-mediated eosinophil recruitment to the esophagus, while others such as histamine may contribute to the abnormal functioning of esophageal musculature through its effect on enteric nerves

IL-5 was shown to be essential in aeroallergen-induced eosinophil recruitment to the esophagus, and IL-15 many also contribute to the same process

IL-13 plays a large role in the up-regulation of genes such as Ki67 and down-regulation of EDCs such as filaggrin and involucrin, which cumulatively contribute to the eotaxin-mediated recruitment of eosinophils to the esophageal epithelium

MBP and eotaxin-3 levels in esophageal biopsies may be more accurate diagnostic biomarkers of EoE

Esophageal epithelial cells are a potent reservoir for cytokines and express receptors such as IL-4 $\alpha, I L-13 R \alpha 1$, and IL-13R $\alpha 2$, making them vulnerable to molecules such as IL-13

\section{CURRENT EFFECTIVE TREATMENTS FOR EOE}

Topical corticosteroids

Fluticasone propionate

Budesonide

Elimination diets

Elemental diets

Esophageal dilation to treat strictures

\section{CONCLUSION}

In summary, EoE is an inflammatory disorder (Table 1) that may be initiated by a hypersensitivity reaction to aero- or food allergens, with a late-phase characterized by eosinophil recruitment and subsequent tissue damage. It is currently characterized by excessive intraepithelial eosinophils, however emerging research shows that increased levels of eosinophildegranulation products (MBP) and eotaxin-3 may be more accurate biomarkers of EoE. EoE has incompletely defined pathophysiology, having characteristics of mainly $\mathrm{T}_{\mathrm{H}} 2$ type immune responses but also includes some $\mathrm{T}_{\mathrm{H}} 1$ cytokines which appear to strongly contribute to tissue fibrosis with esophageal epithelial cells providing a hospitable environment for this inflammatory process.

Eosinophil-degranulation products appear to play a central role in tissue remodeling in EoE. Of note, TGF- $\beta 1, \mathrm{MBP}$, and MMP-9 affect the esophageal epithelium by inducing EMT, interfering with function of esophageal musculature and cellular integrity. This remodeling and dysregulation predisposes to 
fibrosis. Mast-cell-derived molecules such as histamine may affect enteric nerves and may act in concert with TGF- $\beta$ to disrupt the normal functioning of esophageal musculature. Additionally, the esophageal epithelium may facilitate the inflammatory process under pathogenic contexts such as in EoE. Collectively, these contribute to the characteristic histological features of EoE such as subepithelial fibrosis and esophageal thickening, leading to endoscopic findings of luminal narrowing, stricture formation, and trachealization, resulting in symptomatic presentations such as food impactions, dysmotility, and dysphagia. The overall inflammatory response is regulated and propagated with the assistance of eosinophil-derived angiogenic products facilitating recruitment of inflammatory mediators, and also the regulatory functions of molecules such as IL-13 and also mast cells.

The understanding of EoE is still in its infancy. While allergy is implicated, other mechanisms of EoE are also acknowledged in the literature, which implicate mainly eosinophil degranulation and eosinophil-mast-cell cross talk, in disease pathogenesis. While future research may identify possible therapeutic targets, localizing the delivery of these therapies to the esophagus alone remains a challenge. Furthermore, as discussed, emerging evidence suggests a genetic contribution to EoE. This is significant, as recent studies have demonstrated the coexistence of EoE with another genetically inherited condition, CD $(27,28)$. Further research is required to ascertain the effect of $\mathrm{CD}$ on the presentations and treatment outcomes of EoE.

\section{REFERENCES}

1. Moawad FJ, Veerappan GR, Wong RK. Eosinophilic esophagitis. Dig Dis Sci (2009) 54(9):1818-28. doi:10.1007/s10620-009-0873-6

2. Liacouras CA, Spergel JM, Ruchelli E, Verma R, Mascarenhas M, Semeao E, et al. Eosinophilic esophagitis: a 10-year experience in 381 children. Clin Gastroenterol Hepatol (2005) 3(12):1198-206. doi:10.1016/S1542-3565(05)00885-2

3. Attwood SEA, Smyrk TC, Demeester TR. Esophageal eosinophilia with dysphagia. Dig Dis Sci (1993) 38(1):109-16. doi:10.1007/BF01296781

4. Sherrill JD, Rothenberg ME. Genetic dissection of eosinophilic esophagitis provides insight into disease pathogenesis and treatment strategies. J Allergy Clin Immunol (2011) 128(1):23-32. doi:10.1016/j.jaci.2011.03.046

5. Liacouras CA, Bonis P, Putnam PE, Straumann A, Ruchelli E, Gupta SK, et al. Summary of the first international gastrointestinal eosinophil research symposium. J Pediatr Gastroenterol Nutr (2007) 45(3):370-91. doi:10.1097/MPG. 0b013e318142b4f8

6. Dellon ES, Gibbs WB, Fritchie KJ, Rubinas TC, Wilson LA, Woosley JT, et al. Clinical, endoscopic, and histologic findings distinguish eosinophilic esophagitis from gastroesophageal reflux disease. Clin Gastroenterol Hepatol (2009) 7(12):1305-13. doi:10.1016/j.cgh.2009.08.030

7. Li-Kim-Moy JP, Tobias V, Day AS, Leach S, Lemberg DA. Esophageal subepithelial fibrosis and hyalinization are features of eosinophilic esophagitis. J Pediatr Gastroenterol Nutr (2011) 52(2):147-53. doi:10.1097/MPG.0b013e3181ef37al

8. Kagalwalla AF, Sentongo TA, Ritz S, Hess T, Nelson SP, Emerick KM, et al. Effect of six-food elimination diet on clinical and histologic outcomes in eosinophilic esophagitis. Clin Gastroenterol Hepatol (2006) 4(9):1097-102. doi:10.1016/j.cgh.2006.05.026

9. Mishra A, Hogan SP, Brandt EB, Rothenberg ME. An etiological role for aeroallergens and eosinophils in experimental esophagitis. J Clin Invest (2001) 107(1):83-90. doi:10.1172/JCI10224

10. Lucendo AJ, Arias Á, González-Cervera J, Yagüe-Compadre JL, Guagnozzi D, Angueira T, et al. Empiric 6-food elimination diet induced and maintained prolonged remission in patients with adult eosinophilic esophagitis: a prospective study on the food cause of the disease. J Allergy Clin Immunol (2013) 131(3):797-804. doi:10.1016/j.jaci.2012.12.664
11. Teitelbaum JE, Fox VL, Twarog FJ, Nurko S, Antonioli D, Gleich G, et al. Eosinophilic esophagitis in children: immunopathological analysis and response to fluticasone propionate. Gastroenterology (2002) 122(5):1216-25. doi:10. 1053/gast.2002.32998

12. Straumann A, Conus S, Grzonka P, Kita H, Kephart G, Bussmann C, et al. Anti-interleukin-5 antibody treatment (mepolizumab) in active eosinophilic oesophagitis: a randomised, placebo-controlled, double-blind trial. Gut (2010) 59(01):21-30. doi:10.1136/gut.2009.178558

13. Blanchard C, Stucke EM, Rodriguez-Jimenez B, Burwinkel K, Collins MH, Ahrens A, et al. A striking local esophageal cytokine expression profile in eosinophilic esophagitis. J Allergy Clin Immunol (2011) 127(1):208-17. doi:10. 1016/j.jaci.2010.10.039

14. Mishra A, Schlotman J, Wang M, Rothenberg ME. Critical role for adaptive T cell immunity in experimental eosinophilic esophagitis in mice. J Leukoc Biol (2007) 81(4):916-24. doi:10.1189/jlb.1106653

15. Noel RJ, Putnam PE, Rothenberg ME. Eosinophilic esophagitis. N Engl J Med (2004) 351(9):940-1. doi:10.1056/NEJM200408263510924

16. DeBrosse CW, Collins MH, Buckmeier Butz BK, Allen CL, King EC, Assa'ad $\mathrm{AH}$, et al. Identification, epidemiology, and chronicity of pediatric esophageal eosinophilia, 1982-1999. J Allergy Clin Immunol (2010) 126(1):112-9. doi:10. 1016/j.jaci.2010.05.027

17. Sperry SLW, Woosley JT, Shaheen NJ, Dellon ES. Influence of race and gender on the presentation of eosinophilic esophagitis. Am J Gastroenterol (2011) 107(2):215-21. doi:10.1038/ajg.2011.342

18. Hruz P, Straumann A, Bussmann C, Heer P, Simon H-U, Zwahlen M, et al. Escalating incidence of eosinophilic esophagitis: a 20-year prospective, populationbased study in Olten County, Switzerland. J Allergy Clin Immunol (2011) 128(6):1349-50. doi:10.1016/j.jaci.2011.09.013

19. Katzka DA. Demographic data and symptoms of eosinophilic esophagitis in adults. Gastrointest Endosc Clin N Am (2008) 18(1):25-32. doi:10.1016/j.giec. 2007.09.005

20. Straumann A, Spichtin H-P, Grize L, Bucher KA, Beglinger C, Simon HU. Natural history of primary eosinophilic esophagitis: a follow-up of 30 adult patients for up to 11.5 years. Gastroenterology (2003) 125(6):1660-9. doi:10.1053/j.gastro.2003.09.024

21. Almansa C, Krishna M, Buchner AM, Ghabril MS, Talley N, DeVault KR, et al. Seasonal distribution in newly diagnosed cases of eosinophilic esophagitis in adults. Am J Gastroenterol (2009) 104(4):828-33. doi:10.1038/ajg.2008.169

22. Hurrell JM, Genta RM, Dellon ES. Prevalence of esophageal eosinophilia varies by climate zone in the United States. Am J Gastroenterol (2012) 107(5):698-706. doi:10.1038/ajg.2012.6

23. Frederickson NW, Lee Y-J, Redd MK, Go J, Valestin J, Schey R. Su1149 lack of seasonal variation in the incidence of eosinophilic esophagitis. Gastroenterology (2012) 142(5):S-437-S-8.

24. Zink DA, Amin M, Gebara S, Desai TK. Familial dysphagia and eosinophilia. Gastrointest Endosc (2007) 65(2):330-4. doi:10.1016/j.gie.2006.07.021

25. Sant'Anna A, Rolland S, Fournet JC, Yazbeck S, Drouin E. Eosinophilic esophagitis in children: symptoms, histology and $\mathrm{pH}$ probe results. JPediatr Gastroenterol Nutr (2004) 39(4):373-7. doi:10.1097/00005176-200410000-00013

26. Montgomery SM, Lambe M, Wakefield AJ, Pounder RE, Ekbom A. Siblings and the risk of inflammatory bowel disease. Scand J Gastroenterol (2002) 37(11):1301-8. doi:10.1080/003655202761020588

27. Verzegnassi F, Bua J, De Angelis P, Dall'Oglio L, Di Leo G, Ventura A. Eosinophilic oesophagitis and coeliac disease: is it just a casual association? Gut (2007) 56(7):1029-30. doi:10.1136/gut.2006.117986

28. Quaglietta L, Coccorullo P, Miele E, Pascarella F, Troncone R, Staiano A. Eosinophilic oesophagitis and coeliac disease: is there an association? Aliment Pharmacol Ther (2007) 26(3):487-93. doi:10.1111/j.1365-2036.2007.03388.x

29. Rothenberg ME, Spergel JM, Sherrill JD, Annaiah K, Martin LJ, Cianferoni A, et al. Common variants at $5 \mathrm{q} 22$ associate with pediatric eosinophilic esophagitis. Nat Genet (2010) 42(4):289-91. doi:10.1038/ng.547

30. Blanchard C, Wang N, Stringer KF, Mishra A, Fulkerson PC, Abonia JP, et al. Eotaxin-3 and a uniquely conserved gene-expression profile in eosinophilic esophagitis. J Clin Invest (2006) 116(2):536-47. doi:10.1172/JCI26679

31. Liu YJ. TSLP in epithelial cell and dendritic cell cross talk. Adv Immunol (2009) 101:1-25. doi:10.1016/S0065-2776(08)01001-8

32. Challa P. Glaucoma genetics. Int Ophthalmol Clin (2008) 48(4):73. doi:10.1097/ IIO.0b013e318187e71a 
33. Sherrill JD, Gao P-S, Stucke EM, Blanchard C, Collins MH, Putman PE, et al. Variants of thymic stromal lypoprotein and its receptor associate with eosinophilic esophagitis. J Allergy Clin Immunol (2010) 126(1):160-5. doi:10. 1016/j.jaci.2010.04.037

34. Lu TX, Sherrill JD, Wen T, Plassard AJ, Besse JA, Abonia JP, et al. MicroRNA signature in patients with eosinophilic esophagitis, reversibility with glucocorticoids, and assessment as disease biomarkers. J Allergy Clin Immunol (2012) 129(4):1064-75. doi:10.1016/j.jaci.2012.01.060

35. Collins MH, Blanchard C, Abonia JP, Kirby C, Akers R, Wang N, et al. Clinical, pathologic, and molecular characterization of familial eosinophilic esophagitis compared with sporadic cases. Clin Gastroenterol Hepatol (2008) 6(6):621-9. doi:10.1016/j.cgh.2008.01.004

36. Straumann A, Conus S, Degen L, Felder S, Kummer M, Engel H, et al. Budesonide is effective in adolescent and adult patients with active eosinophilic esophagitis. Gastroenterology (2010) 139(5):1526-37. doi:10.1053/j.gastro.2010. 07.048

37. Arora AS, Yamazaki K. Eosinophilic esophagitis: asthma of the esophagus? Clin Gastroenterol Hepatol (2004) 2(7):523-30. doi:10.1016/S1542-3565(04) 00236-8

38. Fox VL, Nurko S, Furuta GT. Eosinophilic esophagitis: it's not just kid's stuff. Gastrointest Endosc (2002) 56(2):260-70. doi:10.1016/S0016-5107(02)70188-0

39. Nairn R, Helbert M. Immunology for Medical Students. Philadelphia, PA: Mosby (2002).

40. Prussin C, Lee J, Foster B. Eosinophilic gastrointestinal disease and peanut allergy are alternatively associated with IL-5+ and IL-5- TH2 responses. J Allergy Clin Immunol (2009) 124(6):1326-32. doi:10.1016/j.jaci.2009.09.048

41. Mulder DJ, Pooni A, Mak N, Hurlbut DJ, Basta S, Justinich CJ. Antigen presentation and MHC class II expression by human esophageal epithelial cells: role in eosinophilic esophagitis. Am J Pathol (2011) 178(2):744-53. doi:10.1016/j.ajpath.2010.10.027

42. Fillon S, Robinson ZD, Colgan SP, Furuta GT. Epithelial function in eosinophilic gastrointestinal diseases. Immunol Allergy Clin North Am (2009) 29(1):171-8. doi:10.1016/j.iac.2008.09.003

43. Aceves SS, Broide DH. Airway fibrosis and angiogenesis due to eosinophil trafficking in chronic asthma. Curr Mol Med (2008) 8(5):350-8. doi:10.2174/ 156652408785161023

44. Kay AB. The role of eosinophils in the pathogenesis of asthma. Trends Mol Med (2005) 11(4):148-52. doi:10.1016/j.molmed.2005.02.002

45. Kagalwalla AF, Akhtar N, Woodruff SA, Rea BA, Masterson JC, Mukkada V, et al. Eosinophilic esophagitis: epithelial mesenchymal transition contributes to esophageal remodeling and reverses with treatment. J Allergy Clin Immunol (2012) 129(5):1387.-1396. doi:10.1016/j.jaci.2012.03.005

46. Gupta SK, Fitzgerald JF, Kondratyuk T, HogenEsch H. Cytokine expression in normal and inflamed esophageal mucosa: a study into the pathogenesis of allergic eosinophilic esophagitis. J Pediatr Gastroenterol Nutr (2006) 42(1):22-6. doi:10.1097/01.mpg.0000188740.38757.d2

47. Lieberman JA, Morotti RA, Konstantinou GN, Yershov O, Chehade M. Dietary therapy can reverse esophageal subepithelial fibrosis in patients with eosinophilic esophagitis: a historical cohort. Allergy (2012) 67(10):1299-307. doi:10.1111/j.1398-9995.2012.02881.x

48. Aceves SS, Newbury RO, Chen D, Mueller J, Dohil R, Hoffman H, et al. Resolution of remodeling in eosinophilic esophagitis correlates with epithelial response to topical corticosteroids. Allergy (2010) 65(1):109-16. doi:10.1111/ j.1398-9995.2009.02142.x

49. Kumar V, Abbas AK, Aster JC. Robbins Basic Pathology. Philadelphia, PA: Elsevier Health Sciences (2012).

50. Aceves SS, Newbury RO, Dohil R, Schwimmer J, Bastian JF. Distinguishing eosinophilic esophagitis in pediatric patients: clinical, endoscopic, and histologic features of an emerging disorder. J Clin Gastroenterol (2007) 41(3):252-6. doi:10.1097/01.mcg.0000212639.52359.f1

51. Aceves SS, Newbury RO, Dohil R, Bastian JF, Broide DH. Esophageal remodeling in pediatric eosinophilic esophagitis. J Allergy Clin Immunol (2007) 119(1):206-12. doi:10.1016/j.jaci.2006.10.016

52. Aceves SS, Ackerman SJ. Relationships between eosinophilic inflammation, tissue remodeling, and fibrosis in eosinophilic esophagitis. Immunol Allergy Clin North Am (2009) 29(1):197-211. doi:10.1016/j.iac.2008.10.003

53. Mishra A, Wang M, Pemmaraju VR, Collins MH, Fulkerson PC, Abonia JP, et al. Esophageal remodeling develops as a consequence of tissue specific IL-5-induced eosinophilia. Gastroenterology (2008) 134(1):204-14. doi:10.1053/j.gastro.2007. 10.002

54. Chehade M, Sampson HA, Morotti RA, Magid MS. Esophageal subepithelial fibrosis in children with eosinophilic esophagitis. J Pediatr Gastroenterol Nutr (2007) 45(3):319-28. doi:10.1097/MPG.0b013e31806ab384

55. Mulder DJ, Pacheco I, Hurlbut DJ, Mak N, Furuta GT, MacLeod RJ, et al. FGF9induced proliferative response to eosinophilic inflammation in oesophagitis. Gut (2009) 58(2):166-73. doi:10.1136/gut.2008.157628

56. Rothenberg ME, Mishra A, Brandt EB, Hogan SP. Gastrointestinal eosinophils. Immunol Rev (2001) 179(1):139-55. doi:10.1034/j.1600-065X.2001.790114.x

57. Mulder DJ, Justinich CJ. Understanding eosinophilic esophagitis: the cellular and molecular mechanisms of an emerging disease. Mucosal Immunol (2011) 4(2):139-47. doi:10.1038/mi.2010.88

58. Stone KD, Prussin C, Metcalfe DD. IgE, mast cells, basophils, and eosinophils. J Allergy Clin Immunol (2010) 125(2):S73-80. doi:10.1016/j.jaci.2009.11.017

59. Lucendo AJ, Bellón T, Lucendo B. The role of mast cells in eosinophilic esophagitis. Pediatr Allergy Immunol (2009) 20(6):512-8. doi:10.1111/j.1399-3038.2008. 00798.x

60. Blanchard C, Mingler MK, Vicario M, Abonia JP, Wu YY, Lu TX, et al. IL-13 involvement in eosinophilic esophagitis: transcriptome analysis and reversibility with glucocorticoids. J Allergy Clin Immunol (2007) 120(6):1292-300. doi:10.1016/j.jaci.2007.10.024

61. Kirsch R, Bokhary R, Marcon MA, Cutz E. Activated mucosal mast cells differentiate eosinophilic (allergic) esophagitis from gastroesophageal reflux disease. J Pediatr Gastroenterol Nutr (2007) 44(1):20-6. doi:10.1097/MPG. Ob013e31802c0d06

62. Yu S, Stahl E, Li Q, Ouyang A. Antigen inhalation induces mast cells and eosinophils infiltration in the guinea pig esophageal epithelium involving histamine-mediated pathway. Life Sci (2008) 82(5):324-30. doi:10.1016/j.lfs. 2007.12.002

63. Rayapudi M, Mavi P, Zhu X, Pandey AK, Abonia JP, Rothenberg ME, et al. Indoor insect allergens are potent inducers of experimental eosinophilic esophagitis in mice. J Leukoc Biol (2010) 88(2):337-46. doi:10.1189/jlb.0110025

64. Montero Vega MT. New aspects on inflammation in allergic diseases. Allergol Immunopathol (2006) 34(4):156-70. doi:10.1157/13091042

65. Sayed BA, Brown MA. Mast cells as modulators of T cell responses. Immunol Rev (2007) 217(1):53-64. doi:10.1111/j.1600-065X.2007.00524.x

66. Abonia JP, Blanchard C, Butz BB, Rainey HF, Collins MH, Stringer K, et al. Involvement of mast cells in eosinophilic esophagitis. J Allergy Clin Immunol (2010) 126(1):140-9. doi:10.1016/j.jaci.2010.04.009

67. Blanchard C, Stucke EM, Burwinkel K, Caldwell JM, Collins MH, Ahrens A, et al. Coordinate interaction between IL-13 and epithelial differentiation cluster genes in eosinophilic esophagitis. J Immunol (2010) 184(7):4033-41. doi:10.4049/jimmunol.0903069

68. Mann NS, Leung JW. Pathogenesis of esophageal rings in eosinophilic esophagitis. Med Hypotheses (2005) 64(3):520-3. doi:10.1016/j.mehy.2004.08.021

69. Konikoff MR, Noel RJ, Blanchard C, Kirby C, Jameson SC, Buckmeier BK, et al. A randomized, double-blind, placebo-controlled trial of fluticasone propionate for pediatric eosinophilic esophagitis. Gastroenterology (2006) 131(5):1381-91. doi:10.1053/j.gastro.2006.08.033

70. Erwin EA, James HR, Gutekunst HM, Russo JM, Kelleher KJ, Platts-Mills TAE. Serum IgE measurement and detection of food allergy in pediatric patients with eosinophilic esophagitis. Ann Allergy Asthma Immunol (2010) 104(6):496-502. doi:10.1016/j.anai.2010.03.018

71. Vicario M, Blanchard C, Stringer KF, Collins MH, Mingler MK, Ahrens A, et al. Local B cells and IgE production in the oesophageal mucosa in eosinophilic oesophagitis. Gut (2010) 59(01):12-20. doi:10.1136/gut.2009.178020

72. Lucendo AJ, Navarro M, Comas C, Pascual JM, Burgos E, Santamaría L, et al. Immunophenotypic characterization and quantification of the epithelial inflammatory infiltrate in eosinophilic esophagitis through stereology: an analysis of the cellular mechanisms of the disease and the immunologic capacity of the esophagus. Am J Surg Pathol (2007) 31(4):598-606. doi:10.1097/01.pas. $0000213392.49698 .8 \mathrm{c}$

73. Mishra A, Hogan SP, Brandt EB, Rothenberg ME. IL-5 promotes eosinophil trafficking to the esophagus. J Immunol (2002) 168(5):2464-9. doi:10.4049/ jimmunol.168.5.2464

74. Spergel JM, Rothenberg ME, Collins MH, Furuta GT, Markowitz JE, Fuchs G III, et al. Reslizumab in children and adolescents with eosinophilic esophagitis: 
results of a double-blind, randomized, placebo-controlled trial. J Allergy Clin Immunol (2012) 129(2):456-63. doi:10.1016/j.jaci.2011.11.044

75. Mishra A, Rothenberg ME. Intratracheal IL-13 induces eosinophilic esophagitis by an IL-5, eotaxin-1, and STAT6-dependent mechanism. Gastroenterology (2003) 125(5):1419-27. doi:10.1016/j.gastro.2003.07.007

76. Rothenberg ME. Biology and treatment of eosinophilic esophagitis. Gastroenterology (2009) 137(4):1238-49. doi:10.1053/j.gastro.2009.07.007

77. Régnier M, Caron D, Reichert U, Schaefer H. Reconstructed human epidermis: a model to study in vitro the barrier function of the skin. Skin Pharmacol Physiol (1992) 5(1):49-56. doi:10.1159/000211017

78. Presland RB, Coulombe PA, Eckert RL, Mao-Qiang M, Feingold KR, Elias PM. Barrier function in transgenic mice overexpressing K16, involucrin, and filaggrin in the suprabasal epidermis. J Invest Dermatol (2004) 123(3):603-6. doi:10.1111/j.0022-202X.2004.23226.x

79. Zhu X, Wang M, Mavi P, Rayapudi M, Pandey AK, Kaul A, et al. Interleukin-15 expression is increased in human eosinophilic esophagitis and mediates pathogenesis in mice. Gastroenterology (2010) 139(1):182.e-93.e. doi:10.1053/j.gastro. 2010.03.057

80. Konikoff MR, Blanchard C, Kirby C, Buckmeier BK, Cohen MB, Heubi JE, et al. Potential of blood eosinophils, eosinophil-derived neurotoxin, and eotaxin-3 as biomarkers of eosinophilic esophagitis. Clin Gastroenterol Hepatol (2006) 4(11):1328-36. doi:10.1016/j.cgh.2006.08.013

81. Bhattacharya B, Carlsten J, Sabo E, Kethu S, Meitner P, Tavares R, et al. Increased expression of eotaxin-3 distinguishes between eosinophilic esophagitis and gastroesophageal reflux disease. Hum Pathol (2007) 38(12):1744-53. doi:10. 1016/j.humpath.2007.05.008

82. Zeisberg M, Kalluri R. Fibroblasts emerge via epithelial-mesenchymal transition in chronic kidney fibrosis. Front Biosci (2008) 13:6991.

83. Hahn C, Islamian AP, Renz H, Nockher WA. Airway epithelial cells produce neurotrophins and promote the survival of eosinophils during allergic airway inflammation. J Allergy Clin Immunol (2006) 117(4):787-94. doi:10.1016/j.jaci. 2005.12.1339

Conflict of Interest Statement: The authors declare that the research was conducted in the absence of any commercial or financial relationships that could be construed as a potential conflict of interest.

Received: 19 February 2014; accepted: 28 April 2014; published online: 30 May 2014. Citation: Raheem M, Leach ST, Day AS and Lemberg DA (2014) The pathophysiology of eosinophilic esophagitis. Front. Pediatr. 2:41. doi: 10.3389/fped.2014.00041

This article was submitted to Pediatric Gastroenterology and Hepatology, a section of the journal Frontiers in Pediatrics.

Copyright () 2014 Raheem, Leach, Day and Lemberg. This is an open-access article distributed under the terms of the Creative Commons Attribution License (CC BY). The use, distribution or reproduction in other forums is permitted, provided the original author(s) or licensor are credited and that the original publication in this journal is cited, in accordance with accepted academic practice. No use, distribution or reproduction is permitted which does not comply with these terms. 